\title{
ASSOCIATION BETWEEN NUTRITIONAL STATUS OF A CHILD USING SCREENING TOOL FOR ASSESSMENT OF MALNUTRITION IN PEDIATRICS AND CLINICAL OUTCOMES IN INPATIENTS AT A TERTIARY CARE HOSPITAL SETTING IN EASTERN NEPAL
}

\author{
Sonia Dahal $1^{*}$, Hemsagar Rimal', Hiralal Sahani ${ }^{3}$, Kumud Pyakurel ${ }^{4}$
}

\begin{abstract}
Affiliation
1. Lecturer, Department of Pediatrics, Birat Medical College and Teaching Hospital, Nepal

2. Professor, Department of Pediatrics, Birat Medical College and Teaching Hospital, Nepal

3. Lecturer, Department of Pediatrics, Birat Medical College and Teaching Hospital, Nepal

4. Assistant Professor, Department of Anesthesiology and Critical care, Birat Medical College and Teaching Hospital, Nepal
\end{abstract}

\section{ARTICLE INFO}

Received : 13 October, 2021
Accepted : 02 January, 2022
Published : 21 February, 2022

(C) Authors retain copyright and grant the journal right of first publication with the work simultaneously licensed under Creative Commons Attribution License CC - BY 4.0 that allows others to share the work with an acknowledgment of the work's authorship and initial publication in this journal.

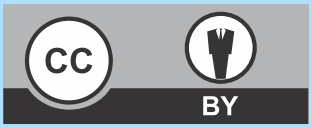

ORA 282

DOI: https://doi.org/10.3126/bjhs.v6i3.43212

* Corresponding Author Dr. Sonia Dahal

Lecturer

Department of Pediatrics

Birat Medical College and Teaching Hospital, Nepal Email: soneedahal@gmail.com

ORCID: https://orcid.org/0000-0003-2803-5216

\section{Citation}

Association Between Nutritional Status of A Child Using Screening Tool for Assessment of Malnutrition in Pediatrics and Clinical Outcomes in Inpatients at A Tertiary Care Hospital Setting in Eastern Nepal. Sonia Dahal, Hemsagar Rimal, Hiralal Sahani, Kumud Pyakurel. BJHS 2021;6(3)16.1631-1635

\section{ABSTRACT}

\section{Introduction}

Malnutrition in children has health and physical consequences resulting in delayed physical growth and motor development, behavioral and social problems as well as susceptibility to contracting diseases. The Screening Tool for Assessment of Malnutrition in Pediatrics (STAMP) is a specially constructed tool that uses anthropometric measurements, body composition, and patient's clinical status to predict the risk of malnutrition for inpatients at admission. There is no agreement on the ideal screening tool or scales for detecting and determining the level of malnutrition in pediatric inpatients. Various studies in the pediatric population have analyzed the association of malnutrition during hospitalization with patient outcomes, but few have analyzed whether the STAMP tool in particular could be used to predict length of hospital stay and disease severity in these patients.

\section{Objectives}

We studied the use of STAMP screening tools to assess the risk of malnutrition in inpatients by including a nutritional screening in the admission process and analyze the association between the risk of malnutrition and patient outcomes (length of hospital stay and severity of disease).

\section{Methodology}

We conducted a prospective single-center study between May to July 2021 at a tertiary care hospital. All patients admitted to the pediatric ward aged 1 month to 15 years with a length of stay of at least 24 hours were included into the study. Data were collected about clinical, anthropometric and demographic variables for each patient including STAMP grading, length of hospital stay and severity of disease.

\section{Results}

Our study suggests comparable demographic and other patient-related variables in the three categories (mild, moderate and severe) of STAMP grading ( $p$-value $>0.05$ ). STAMP grading was not significantly associated with both length of hospital stay and severity of disease.

\section{Conclusion}

The use of STAMP as a malnutrition screening tool for pediatric inpatients is not significantly associated with length of stay or severity of disease.

\section{KEYWORDS}

Length of hospital stay, Malnutrition, Pediatrics, Severity of disease, STAMP tool 


\section{INTRODUCTION}

Malnutrition of children has always been a global concern. Health and physical consequences of malnourishment in children are delay in their physical growth and motor development; lower intellectual quotient (IQ), greater behavioral problems and deficient social skills; susceptibility to contracting diseases and the list goes on. ${ }^{1,2}$ The 2017 data from the Ministry of Health and Population of Nepal suggests 1 million children under 5 years (36\%) suffer from chronic malnutrition (stunting or low height-for-age) and 10 $\%$ suffer from acute malnutrition (wasting or low weight-forheight). ${ }^{3}$ Along with malnutrition the burden of infectious diseases (pneumonia, diarrhea) resulting in hospital admissions is more. Children may present with a degree of malnutrition at the time of hospital admission. On top of it, pediatric malnutrition, before and during hospital admission could elevate morbidity and influence the clinical outcomes of disease. When admitted in hospital, they are generally not subjected to anthropometric assessment therefore may not receive nutritional support. ${ }^{4,5}$ Measuring a child's growth is one of the most efficient ways of assessing their general state of health, making effective interventions possible that can reestablish ideal conditions for health and avoid the damage resulting from malnutrition. ${ }^{6}$ Nutritional assessment of hospitalized children is very often neglected, contributing to the occurrence of complications and prolonged hospital stays.

There are different tools to assess the risk of malnutrition in hospitalized children. The World Health Organization (WHO) classification for malnutrition or the Waterlow classification is widely used in our setting as a screening tool for classification of malnutrition in pediatrics. The Screening Tool for the Assessment of Malnutrition in Pediatrics (STAMP) developed by McCarthy et al $^{7}$ is a specially designed tool to determine nutritional risk for inpatients at admission. STAMP is a nutritional screening tool that uses anthropometric measurements, body composition and the clinical condition of the patient. It has a high sensitivity $(90 \%)$ but a low specificity. ${ }^{8}$ There is no consensus on the optimal screening method or the scales that should be used to detect and establish the level of malnutrition in pediatric inpatients $^{9-11}$ but previous studies have recommended the use of these tools even in outpatients at the primary care level. ${ }^{12}$

Various studies in the pediatric population have analyzed the association of malnutrition during hospitalization with patient outcomes, but only few have analyzed whether the STAMP in particular could be used to predict outcomes and severity in these patients. The main objective of our study was to use the STAMP screening tool to assess risk of malnutrition in inpatients by including a nutritional screening in the admission process to analyze the association between the degree of malnutrition and patient outcomes (length of hospital stay and disease severity) during the hospital stay.

\section{METHODOLOGY}

This prospective single-center study was conducted at Birat Medical College Teaching Hospital between May to July 2021. All consecutive patients admitted to the pediatric ward aged 1 month to 15 years with a length of stay of at least 24 hours were included into the study after consent of their guardian. Patients in other pediatric specialties (cardiology, nephrology, oncology and hematology), patients aged $<1$ month and postoperative patients were excluded from the study. Each patient's clinical and demographic data, including anthropometric measurements of weight (in kg), height or length (in $\mathrm{cm}$ ), and body mass index (BMI), were recorded on the day of admission. Using calibrated SECA $\mathrm{GmbH} 375^{\circledR}$ baby scales, patients were weighed naked or lightly clothed in the decubitus position for children under 2 years and standing for older children. A stadiometer was used to measure length of the patient as the distance between the top of head and heel of patients under the age of 2 years. Height of children aged more than 2 years was measured with a patient standing with a column scale. We documented the weight for height (WFH), height for age (HFA) and BMI percentile based on the growth tables by WHO. Disease was considered severe if a patient required admission to the pediatric intensive care unit (PICU), WoodDownes clinical scoring system (severity $\geq 8$ ) in patients with bronchiolitis or pulmonary score in patients with asthma exacerbations (severity $\geq 7$ ). The risk of malnutrition was assessed using the STAMP screening tool for malnutrition (http://www.stampscreeningtool.org)

Collected data were analyzed with SPSS version 22 (IBM SPSS Statistics; Armonk, NY, USA). The Kruskal-Wallis test was used to analyze quantitative variables, while the Chi square or Fisher exact test was used to analyze categorical variables. The data is expressed as a median and interquartile range (IQR) or as a frequency.

\section{RESULTS}

This study was carried out at Birat Medical College Teaching Hospital after approval from the institutional review committee. A total of 153 patients fulfilling the inclusion criteria within the study period were enrolled for the study where 127 patients were enlisted for the final analysis. In total, 27 patients had severe disease with median length of stay for the study population was 6 days with IQR ranging from 4-7 days.

The results of our study suggest comparable demographic and other patient variable across the three categories (mild, moderate and severe) of STAMP grading ( $p$-value $>0.05$ ), thus usage of STAMP grading was not significantly different across the data (Table 1 and 2). Table 3 and 4 suggest STAMP grading and other nutritional parameters (BMI percentile, HFA and WFH) were not associated with both length of hospital stay and severity of disease. Thus, our study suggests the risk of malnutrition given by STAMP screening tool do not associate significantly to both length of hospital stay and disease severity. 
Table 1: Demographics and patient data versus STAMP score

\begin{tabular}{|c|c|c|c|c|c|}
\hline \multirow{2}{*}{\multicolumn{2}{|c|}{ Particulars }} & \multicolumn{3}{|c|}{ STAMP score } & \multirow{2}{*}{ p-Value } \\
\hline & & \multirow{2}{*}{$\begin{array}{c}0-1 \\
4\end{array}$} & \multirow{2}{*}{$\frac{2-3}{6}$} & \multirow{2}{*}{$\begin{array}{l}\geq 4 \\
0\end{array}$} & \\
\hline \multirow{5}{*}{ Age (months) } & $1-12$ & & & & \multirow{5}{*}{0.251} \\
\hline & $13-24$ & 7 & 21 & 1 & \\
\hline & $25-60$ & 18 & 17 & 2 & \\
\hline & $61-120$ & 14 & 27 & 2 & \\
\hline & $121-192$ & 3 & 5 & 0 & \\
\hline \multirow{2}{*}{ Gender } & Male & 23 & 44 & 4 & \multirow{2}{*}{0.377} \\
\hline & Female & 23 & 32 & 1 & \\
\hline \multirow{2}{*}{ Immunization } & Yes & 45 & 76 & 5 & \multirow{2}{*}{0.412} \\
\hline & No & 1 & 0 & 0 & \\
\hline \multirow{2}{*}{ Weight loss } & Yes & 6 & 7 & 0 & \multirow{2}{*}{0.591} \\
\hline & No & 40 & 69 & 5 & \\
\hline \multirow{2}{*}{$\begin{array}{l}\text { Appetite } \\
\text { decrease }\end{array}$} & Yes & 8 & 10 & 0 & \multirow{2}{*}{0.527} \\
\hline & No & 38 & 66 & 5 & \\
\hline \multirow{2}{*}{ Recent Illness } & Yes & 4 & 7 & 0 & \multirow{2}{*}{0.778} \\
\hline & No & 42 & 69 & 5 & \\
\hline \multirow{2}{*}{$\begin{array}{c}\text { Underlying } \\
\text { disease }\end{array}$} & Yes & 1 & 11 & 0 & \multirow{2}{*}{0.061} \\
\hline & No & 45 & 65 & 5 & \\
\hline \multirow{6}{*}{ Diagnosis } & Respiratory & 17 & 37 & 2 & \multirow{6}{*}{0.266} \\
\hline & Gastrointestinal & 7 & 10 & 2 & \\
\hline & Infectious & 16 & 19 & 1 & \\
\hline & Allergic & 2 & 0 & 0 & \\
\hline & Neurologic & 1 & 8 & 0 & \\
\hline & Hematogenic & 3 & 2 & 0 & \\
\hline \multicolumn{2}{|c|}{ Length of stay (Median (IQR)) } & $5(4-7)$ & $6(4-7)$ & $6(6-6)$ & 0.994 \\
\hline
\end{tabular}

Table 2: Nutritional parameters versus STAMP score (parameters expressed as Median (IQR))

\begin{tabular}{|c|c|c|c|c|}
\hline \multirow{2}{*}{ Particulars } & \multicolumn{3}{|c|}{ STAMP score } & $\begin{array}{c}\text { p- } \\
\text { Value }\end{array}$ \\
\cline { 2 - 4 } & $\mathbf{0 - 1}$ & $\mathbf{2 - 3}$ & $\geq 4$ & 0.439 \\
\hline BMI & $16(14.5-17.1)$ & $\begin{array}{c}15.6 \\
(13.5-17.22)\end{array}$ & $13(11.6-17.2)$ & 0.779 \\
\hline WFH & $\begin{array}{c}100.67 \\
(88.89-107.52)\end{array}$ & $\begin{array}{c}95.23 \\
(83.33-109.89)\end{array}$ & $\begin{array}{c}97.49-111.11) \\
(81.49\end{array}$ & 0.362 \\
\hline HFA & $\begin{array}{c}95.72 \\
(87.99-103.3)\end{array}$ & $\begin{array}{c}96.46 \\
(93.36-103.77)\end{array}$ & $\begin{array}{c}100.36 \\
(98.06-100.36)\end{array}$ & 0.613 \\
\hline $\begin{array}{c}\text { BMI } \\
\text { percentile }\end{array}$ & $\begin{array}{c}16.6 \\
(1.55-70.37)\end{array}$ & $15.9(2.3-33)$ & $0.3(0.1-81.9)$ & 0.639 \\
\hline
\end{tabular}

\section{DISCUSSION}

Malnutrition is associated with increased length of hospital stay, morbidity and mortality, infection risk, and increased hospital costs when compared with well-nourished children. ${ }^{13-17}$ STAMP grading is a tool intended to be used to assess the risk of malnutrition for hospitalized children. The advantage of this tool is one-time assessment of patients generally at the time of hospital admission. This is significantly important as STAMP could also be used for children during the outpatient visit as well. Thus, this study was relevant to assess whether risk of malnutrition given by STAMP would be able to be related to length of hospital stay and severity of disease thereby highlighting its importance clinically as well. The results of our study however have demonstrated that risk of malnutrition given by STAMP cannot be related to both length of hospital stay ( $\geq 5$ days) or severity of disease.

The median length of hospital stay of our study population
Table 3: Length of hospital stay versus STAMP score, BMI percentile, WFH, HFA

\begin{tabular}{|c|c|c|c|c|}
\hline \multirow{2}{*}{\multicolumn{2}{|c|}{ Particulars }} & \multicolumn{2}{|c|}{$\begin{array}{l}\text { Length of Stay } \\
\geq 5 \text { days }\end{array}$} & \multirow[t]{2}{*}{ p-Value } \\
\hline & & Yes & No & \\
\hline \multirow{3}{*}{$\begin{array}{l}\text { STAMP } \\
\text { score }\end{array}$} & $0-1$ & 24 & 22 & \multirow{3}{*}{0.386} \\
\hline & $2-3$ & 36 & 40 & \\
\hline & $\geq 4$ & 1 & 4 & \\
\hline \multirow{4}{*}{$\begin{array}{c}\text { BMI } \\
\text { Percentile }\end{array}$} & Normal (5-85) & 30 & 27 & \multirow{4}{*}{0.193} \\
\hline & Underweight $(<5)$ & 16 & 18 & \\
\hline & Overweight (86-95) & 1 & 0 & \\
\hline & Obese (>95) & 2 & 8 & \\
\hline \multirow{4}{*}{ WFH } & Normal (>95) & 28 & 29 & \multirow{4}{*}{0.11} \\
\hline & Mild (90-95) & 1 & 7 & \\
\hline & Moderate (85-90) & 11 & 6 & \\
\hline & Severe $(<85)$ & 10 & 12 & \\
\hline \multirow{4}{*}{ HFA } & Normal $(>90)$ & 39 & 40 & \multirow{4}{*}{0.177} \\
\hline & Mild (80-90) & 5 & 8 & \\
\hline & Moderate (70-80) & 0 & 5 & \\
\hline & Severe $(<70)$ & 1 & 1 & \\
\hline
\end{tabular}

Table 4: Disease severity versus STAMP score, BMI percentile, WFH, HFA

\begin{tabular}{|c|c|c|c|c|}
\hline \multirow{2}{*}{\multicolumn{2}{|c|}{ Particulars }} & \multicolumn{2}{|c|}{$\begin{array}{l}\text { Disease } \\
\text { Severity }\end{array}$} & \multirow[t]{2}{*}{ p-Value } \\
\hline & & Yes & No & \\
\hline \multirow{3}{*}{$\begin{array}{c}\text { STAMP } \\
\text { score }\end{array}$} & $0-1$ & 9 & 37 & \multirow{3}{*}{0.568} \\
\hline & $2-3$ & 16 & 60 & \\
\hline & $\geq 4$ & 2 & 3 & \\
\hline \multirow{4}{*}{$\begin{array}{c}\text { BMI } \\
\text { Percentile }\end{array}$} & Normal (5-85) & 30 & 27 & \multirow{4}{*}{0.193} \\
\hline & Underweight $(<5)$ & 16 & 18 & \\
\hline & Overweight (86-95) & 1 & 0 & \\
\hline & Obese $(>95)$ & 2 & 8 & \\
\hline \multirow{4}{*}{ WFH } & Normal (>95) & 11 & 46 & \multirow{4}{*}{0.669} \\
\hline & Mild (90-95) & 3 & 5 & \\
\hline & Moderate (85-90) & 3 & 14 & \\
\hline & Severe $(<85)$ & 5 & 17 & \\
\hline \multirow{4}{*}{ HFA } & Normal $(>90)$ & 16 & 63 & \multirow{4}{*}{0.903} \\
\hline & Mild (80-90) & 3 & 10 & \\
\hline & Moderate (70-80) & 1 & 4 & \\
\hline & Severe $(<70)$ & 0 & 2 & \\
\hline
\end{tabular}

was 6 days. The result of our study is in line with a study by Pérez-SolísD where length of hospital stay of 3 days duration was not associated with the STAMP grading. ${ }^{18}$ Our results differ from a previous study with similar methodology to ours where length of hospital stay of 3 or more days has been reported to be associated with STAMP grading. ${ }^{19}$ It is to be noted that median length of hospital stay for the above study was 3 days while in our findings was 6 days. Reanalysis of our data revealed a significant association between length of hospital stay of 3 days or more with STAMP grading.

The results of our study could be explained by two reasons. Firstly, STAMP is a screening tool with generally high sensitivity and low specificity to predict malnutrition as 
given by various studies. ${ }^{8}$ This observation suggests that the STAMP tool is likely to over diagnose nutritional risk in hospitalized children, thus could have led to our nonsignificant results. This was highlighted in a recent study by Lesego $\mathrm{N}$ et al. ${ }^{20}$ The authors in this study observed STAMP grading to be non-significantly related with length of hospital stay. In the same study, when they used a modified STAMP tool that increased the prediction of malnutrition, they found significant correlation with length of hospital stay. Secondly, length of hospital stay has a multifactorial causation and a causal relationship between different variables has not been demonstrated. ${ }^{21}$

Our study suggests no clinical significance between the association of disease severity and STAMP grading. This is in contrast to a previous study with similar methodology to ours where significant association between STAMP grading and severity of disease was noted. ${ }^{19}$ A closer inspection to our data revealed 27 patients had severe disease and 5 patients had STAMP more than or equal to 4 . Our study reveals $19.5 \%$ and $21 \%$ of patients respectively had mild and moderate STAMP grading whereas the above study had $1.3 \%$ and $7 \%$. We believe the discrepancy between the data could be related to hospital admission criteria and difference between the endemic and seasonal diseases, thus influencing the results.

\section{LIMITATION OF THE STUDY}

There are some limitations in the study. Firstly, though our hospital is a tertiary referral center with a diverse set of

\section{REFERENCES}

1. FAO. The state of food insecurity in the world 2008[Internet]. 2008 Available from: https://www.fao.org/3/i0291e/i0291e00.pdf

2. Black RE, Morris SS, Bryce J. Where and why are 10 million children dying every year? Lancet. 2003 Jun 28;361(9376):2226-34. doi: 10.1016/S0140-6736(03)13779-8. PMID: 12842379.

3. Ministry of Health, Nepal; New ERA; and ICF. Nepal Demographic and Health Survey, 2016. 2017.

4. Sermet-Gaudelus I, Poisson-Salomon AS, Colomb V, Brusset MC, Mosser F, Berrier F, Ricour C. Simple pediatric nutritional risk score to identify children at risk of malnutrition. Am J ClinNutr. 2000 Jul;72(1):64-70. doi: 10.1093/ajcn/72.1.64. PMID: 10871562.

5. Kac G, Camacho-Dias P, Silva-Coutinho D, Silveira-Lopes R, Marins VV, Pinheiro $A B$. Length of stay is associated with incidence of in-hospital malnutrition in a group of low-income Brazilian children. SaludPublica Mex. 2000 Sep-Oct;42(5):407-12. doi: 10.1590/s003636342000000500006. PMID: 11125625.

6. Hulst JM, Zwart H, Hop WC, Joosten KF. Dutch national survey to test the STRONGkids nutritional risk screening tool in hospitalized children. ClinNutr. 2010 Feb;29(1):106-11. doi: 10.1016/j.clnu. 2009.07.006. Epub 2009 Aug 13. PMID: 19682776.

7. McCarthy H, Dixon M, Crabtree I, Eaton-Evans MJ, McNulty H. The development and evaluation of the Screening Tool for the Assessment of Malnutrition in Pediatrics (STAMPC) for use by healthcare staff. J Hum Nutr Diet. 2012 Aug;25(4):311-8. doi: 10.1111/j.1365277X.2012.01234.x. Epub 2012 May 9. PMID: 22568534. patients seeking medical assistance all year round, limited number of participants involved in the study over 3 months of study period limits randomization of the overall population. Secondly, cross checking with standard dietetic evaluation for malnutrition would have enlightened the prediction potential of STAMP in our study population, thus confirming our findings.

\section{CONCLUSION}

The use of STAMP screening tool to assess the risk of malnutrition in inpatients by including a nutritional screening in the admission process does not associate significantly with length of hospital stay or severity of disease.

\section{RECOMMENDATION}

Further studies with overall longer duration for sample collection, higher number of participants and correlation of finding with standard dietetic evaluation for malnutrition is recommended to negate the limitations of the present study.

\section{ACKNOWLEDGEMENTS}

Sincere thanks to all the participants and colleagues for their contribution and cooperation for this study.

\section{CONFLICTS OF INTEREST}

None

\section{FINANCIAL DISCLOSURE}

\section{None}

8. Teixeira AF, Viana KD. Nutritional screening in hospitalized pediatric patients: a systematic review. J Pediatr (Rio J). 2016 Jul-Aug;92(4):343-52. doi: 10.1016/j.jped.2015.08.011. Epub 2016 Feb 6. PMID: 26859247.

9. Joosten KF, Hulst JM. Nutritional screening tools for hospitalized children: methodological considerations. ClinNutr. 2014 Feb;33(1):1-5. doi: 10.1016/j.clnu.2013.08.002. Epub 2013 Aug 31. PMID: 24050847.

10. Moeeni V, Walls T, Day AS. Nutritional status and nutrition risk screening in hospitalized children in New Zealand. ActaPaediatr. 2013 Sep;102(9): e419-23. doi: 10.1111/apa.12299. Epub 2013 Jun 3. PMID: 23692547.

11. Moeeni V, Walls T, Day AS. Assessment of nutritional status and nutritional risk in hospitalized Iranian children. ActaPaediatr. 2012 Oct;101(10):e446-51. doi: 10.1111/j.1651-2227.2012.02789.x. Epub 2012 Aug 4. PMID: 22804864.

12. Rub G, Marderfeld L, Poraz I, Hartman C, Amsel S, Rosenbaum I, Pergamentzev-Karpol S, Monsonego-Ornan E, Shamir R. Validation of a Nutritional Screening Tool for Ambulatory Use in Pediatrics. J PediatrGastroenterolNutr. 2016 May;62(5):771-5. doi: 10.1097/MPG. 0000000000001046 . PMID: 26628448.

13. Secker DJ, Jeejeebhoy KN. Subjective Global Nutritional Assessment for children. Am J ClinNutr. 2007 Apr;85(4):1083-9. doi: 10.1093/ajcn/ 85.4.1083. PMID: 17413109.

14. Hecht C, Weber M, Grote V, Daskalou E, Dell'Era L, Flynn D, Gerasimidis K, Gottrand F, Hartman C, Hulst J, Joosten K, Karagiozoglou-Lampoudi T, Koetse HA, Kolaček S, Książyk J, Niseteo T, Olszewska K, Pavesi P, Piwowarczyk A, Rousseaux J, Shamir R, Sullivan PB, Szajewska H, Vernon Roberts A, Koletzko B. Disease associated malnutrition correlates with length of hospital stay in children. ClinNutr. 2015 Feb;34(1):53-9. doi: 10.1016/j.clnu.2014.01.003. Epub 2014 Jan 11. PMID: 24461472. 
15. Chen MY, Yang YJ. Being Underweight Is an Independent Risk Factor for Poor Outcomes Among Acutely Critically III Children. NutrClin Pract. 2018 Jun;33(3):433-438. doi: 10.1177/ 0884533617712225. Epub 2017 Dec 14. PMID: 28671859.

16. Mezoff A, Gamm L, Konek S, Beal KG, Hitch D. Validation of a nutritional screen in children with respiratory syncytial virus admitted to an intensive care complex. Pediatrics. 1996 Apr;97(4):543-6. PMID: 8632943

17. Einloft PR, Garcia PC, Piva JP, Bruno F, Kipper DJ, Fiori RM. Perfilepidemiológico de dezesseisanos de umaunidade de terapiaintensivapediátrica [A sixteen-year epidemiological profile of a pediatric intensive care unit, Brazil]. Rev SaudePublica. 2002 Dec;36(6):728-33. Portuguese. doi: 10.1590/s003489102002000700011. PMID: 12488940.

18. Pérez-Solís D, Larrea-Tamayo E, Menéndez-Arias C, MolinosNorniella C, Bueno-Pardo S, Jiménez-Treviño S, Bousoño-Garcia C, Díaz-Martín JJ. Assessment of Two Nutritional Screening Tools in Hospitalized Children. Nutrients. 2020 Apr 26;12(5):1221. doi: 10.3390/nu12051221. PMID: 32357543; PMCID: PMC7281986.
19. Pérez Moreno J, de la Mata Navazo S, López-HerceArteta E, TolínHernani M, González Martínez F, González Sánchez MI, Rodríguez Fernández R. Influencia del estadonutricional en la evoluciónclínica del niñohospitalizado [Influence of nutritional status on clinical outcomes in hospitalised children]. AnPediatr (Engl Ed). 2019 Nov;91(5):328-335. Spanish. doi: 10.1016/j.anpedi. 2019.01. 014. Epub 2019 Oct 5. PMID: 31591004.

20. LesegoNdhlovu, Tim De Maayer. Introducing a nutritional risk screening tool in a South African hospital. South African Journal of Clinical nutrition. 2021:1-7. doi: 10.1080/16070658.2021.1940718.

21. Huysentruyt K, Devreker T, Dejonckheere J, De Schepper J, Vandenplas Y, Cools F. Accuracy of Nutritional Screening Tools in Assessing the Risk of Undernutrition in Hospitalized Children. J PediatrGastroenterolNutr. 2015 Aug;61(2):159-66. doi: 10.1097/MPG.0000000000000810. PMID: 25885879. 